\title{
The Effects of Seat Surface Inclination on Forward Reaching in Children with Spastic Cerebral Palsy
}

\author{
Jeong Yun Jeong ${ }^{1}$, Ho-Cheol Lee ${ }^{2}$, Hwa-Kyung Shin ${ }^{3}$ \\ 'Department of Physical Therapy, Graduate School of Medical Science, Catholic University of Daegu; ${ }^{2}$ School of Mechanical and Automotive \\ Engineering, College of Engineering, Catholic University of Daegu; ${ }^{3}$ Department of Physical Therapy, College of Medical Health, Catholic University \\ of Daegu, Daegu, Korea
}

\begin{abstract}
Purpose: Impaired reaching movement is commonly observed in children with cerebral palsy. The purpose of this study was to determine whether the inclination of seat surface can influence the reaching movement in children with spastic diplegic cerebral palsy (CP).

Methods: The subjects were 31 children, 16 children with spastic bilateral CP and 15 typically developing (TD) children. The children performed static sitting and forward reaching under three conditions: a horizontal seat surface (Horizontal $0^{\circ}$ ), a seat surface inclined anterior 15 degrees (Ant $15^{\circ}$ ), and a seat surface inclined posterior 15 degrees (Post 15'). A 3-axis accelerometer ('ZSTAR3') was used for analysis of the reaching movement. A 3-axis accelerometer was attached on the manubrium of the sternum, lateral epicondyle of the humerus, and styloid process of the ulna. We measured the reaction time, movement time, and data amount during reaching the $8 \mathrm{~cm}$ target with an index finger on the three inclined seat surfaces.

Results: Reaction time and movement time for CPs showed significant delay; comparing the TD's and CP's amount was significantly greater than the TD's during reaching task $(p<0.05)$. In particular, CP's reaction time and movement time on a seat surface inclined Ant $15^{\circ}$ was significantly more delayed compared with the other seat surfaces $(p<0.05)$.

Conclusion: Our results suggest that seat-inclination intervention may provide an ergonomic approach for children with spastic cerebral palsy.
\end{abstract}

Keywords: Accelerometer, Cerebral palsy, Reaching, Seat surface inclination

\section{서 론}

상지는 환경 탐색 및 다른 사람의 신체나 사물과의 접촉을 위한 상호 작용에 사용되며, 대부분의 일상생활을 영위하는 데 결정적인 역할 을 하게 된다. 상지기능을 결정하는 중요한 요소 중 하나는 팔 뻗기 (reaching)이다. 팔 뻗기는 손을 이용한 조작과 결합되는 복잡한 과정 으로 많은 행동들의 발달과 직접적인 관련이 있으며, 근 골격계와 신 경계의 발달과 상호작용, 반복적인 경험을 통해 획득된다. 일반적으 로 정상발달 아동은 생후 2 개월째 목 근육을 조절하면서 머리와 팔 의 움직임이 매우 강하게 짝을 이룸으로써, 처음 팔 뻗기를 시도하고, 약 4 개월째 체간을 안정시키면서 좀 더 안정적인 기저면에서 팔 뻗기 를 할 수 있게 된다. 그리고 생후 1 년 동안 다양한 변화를 거듭하면서 팔뻗기는 완성된다.2

팔 뺃기는 안정성과 방향성이라는 목적을 성취하기 위해 공간에
서 신체의 위치를 조절하는 자세조절, 팔을 뻔는 목적이나 과제의 특 성에 따른 과제 의존적 조절에 영향을 받는다. ${ }^{3}$ Levin 등은 상지의 작 업능력을 위해 체간을 통한 자세조절이 커다란 영향을 미친다고 하 였다. Shumway과 Woollacott ${ }^{3}$ 은 과제의 목표에 따라 팔을 뻗는 속도 의 변화와 움직임을 지속하는 시간은 조절된다고 하였으며, Fitts ${ }^{5}$ 는 팔 동작의 정밀성이나 동작의 거리가 증가할 때 동작시간은 길어진 다고 하였다. 따라서 효율적인 팔 뻗기를 위해서는 근골격계와 신경 계의 발달에 함께 정확한 운동 조절 능력이 필요하다. 하지만 조화로 운 발달과 함께 미성숙한 뇌의 손상으로 운동발달과 자세이상을 보 이는 뇌성마비 아동들은 신경계와 근골격계의 발달이 지연되고, 비 정상적 근긴장도, 근력 약화, 운동 실조, 협응력 장애 등의 문제로 조 절된 팔 뻗기를 수행하는데 어려움이 많다. ${ }^{6}$ 경직성 양하지 뇌성마비 아동은 상지기능이 하지 기능보다 우수하여 독립적인 상지 움직임 을 기대할 수 있지만 몸통부위의 낮은 근 긴장도로 인해 자세 안정성
Received March 24, 2015 Revised April 20, 2015

Accepted April 21, 2015

Corresponding author Hwa-Kyung Shin

E-mail hkshin1@cu.ac.kr
Copylight (C)2015 The Korea Society of Physical Therapy

This is an Open Access article distribute under the terms of the Creative Commons Attribution Non-commercial License (Http:// creativecommons.org/license/by-nc/3.o.) which permits unrestricted non-commercial use, distribution, and reproduction in any medium, provided the original work is properly cited. 
이 결여되고 하지의 경직으로 운동성이 떨어진다. ${ }^{6}$ 그러나 예상과는 달리 경부, 상지, 상부 체간등을 이용한 보상작용은 오히려 상지기능 을 저하시키는 경우를 쉽게 발견할 수 있다. 이에 아동들은 손에 쥔 물체를 잘 떨어뜨리고, 자주 물체에 부딪혀 상처를 입고, 또래 아이들 과 놀이를 즐길 수 없어 적극적이지 못하며 일상생활 활동에 어려움 을 느끼게 된다. ${ }^{78}$ 그럼에도 불구하고 경직성 양하지 뇌성마비 아동 의 상지 기능의 손상은 하지에 비해 주목받지 못하고 있는 실정이다. ${ }^{9}$

현재 뇌성마비 아동의 상지 기능을 개선시키기 위하여 자세(positioning), 앉기자세 보조기구(adaptive seating device), 보장구(orthotic device) 등 다각적인 방면에서 연구가 진행되어 왔다.7.8 그러나 에너지 보존을 높이고 상지 기능을 최적화 시키기 위한 가장 최선의 앉기 자 세에 관해서는 아직까지 논쟁의 여지가 있다. 전방경사 의자는 뇌성 마비 아동의 자세조절과 호흡에 긍정적인 효과를 나타는내는 것으 로 보고 되었다. 자세 안정성을 위한 앉은 자세의 방향성(orientation) 에 대한 고려는 뇌성마비 아동에서 적용되어져왔다. 앉기 자세의 방 향성은 일상생활의 대부분을 휄체어 의존하는 뇌성마비 아동의 기 능 향상에 영향을 미칠 수 있다. 특히, 전방경사 의자는 뇌성마비 아 동의 자세 안정성과 호흡 기능에 영향을 영향을 미칠 수 있다고 보고 되었다. 그럼에도 불구하고, 의사 경사도에 따른 앉기 자세의 효율성 에 대해서는 정확하게 알려져있지 않다. ${ }^{3}$ 그러므로 본 연구에서 세 종류의 의자 경사도에 의한 인간공학적 접근이 경직성 양하지 뇌성 마비 아동의 전방 팔뻗기 수행 능력에 미치는 영향에 관하여 알아보 고자한다.

\section{연구방법}

\section{1. 연구 대상}

본 연구는 경직성 양하지 뇌성마비(spastic bilateral cerebral palsy, CP) 아동과 정상발달아동(typical development, TD)을 대상으로 하였다. 대상자는 경직성 양하지 마비 아동 16 명, 정상 아동 15 명이었고 대상 자 선정 조건은 다음과 같다. 경직성 양하지 뇌성마비 아동은 첫째, 독립적인 앉기가 가능하고, 자가 이동 동작이 가능하며, 대동작 기능 분류 시스템(Gross Motor Function Classification System, GMFCS)의 IV 등급 이상에 속하는 아동, 둘째, 기능적 측정 독립도구(Wee Functional Independence Measure, Wee FIM)를 통한 인지평가 부분에서 15 점 이상으로 검사자의 지시에 따라 평가항목을 수행할 수 있는 아동, 셋째, 안과적 질환에 문제가 없고, 최근 6 개월 이내에 상지에 관련된 수술 혹은 시술을 하지 않은 아동을 선정하였다. 정상발달 아동은 신경학적 이상이나 근골격계적 병변이 없는 아동으로 선정하였다. 실험 전 본 연구의 목적과 방법에 대하여 보호자에게 설명 후 동의를 받았다.

\section{2. 실험 기구 및 방법}

팔뻗기 시 움직임을 감지하기 위해 무선 삼축 가속도계 센서인 ZSTAR3 (Frescale, USA)를 사용하였다. 이 장비는 신체에 부착하는 센서 보드(sensor board)와 센서보드의 신호를 감지하는 외장메모리 (UBS)로 구성되어 있다. 센서 보드는 떨어짐(fall), 기울임(tilt), 흔들림 (motion), 위치변화(positioning), 진동(shock), 떨림(vibration)의 6가지 형태의 움직임을 감지하여 일정 수준 이상의 움직임 발생 시 값을 수 집하고 그룹화 하는 특징이 있다(Figure 1). 수집된 값은 엑셀파일로 자동 저장되며, MATLAB ver 7. 12.0 프로그램을 이용하여 각 위치 센 서의 정보를 좌표로 전환하여 분석하였다.

실험 과제는 3 가지 각도의 의자에 앉아서 각각의 자세에서 목표물 을 향해 팔을 뻗는 것이다. 3 가지 의자 경사는 각도와 높이가 조절되 고 등받이가 없는 벤치를 사용하여 전방 $15^{\circ}$ 경사 $\left(15^{\circ}\right.$ of anterior inclination), 수평 $\left(0^{\circ}\right.$ horizontal of inclination), 후방 $15^{\circ}$ 경사 $\left(15^{\circ}\right.$ of posterior inclination)를 만들었다. 아동은 의자 위에 편안하게 앉아 양손은 허 벅지 위에 가볍게 올려 두었으며, 양발은 바닥에 편안하게 지지하였 으며, 필요한 경우 발판을 이용하였다. 화면과의 거리는 자신의 팔 길 이의 $120 \%$, 높이는 어깨 높이에 위치하도록 하였으며, 대상자 간의 차 이에 대한 영향을 최소화하기 위해 책상의 높이와 의자의 높이를 조 절하였고, 거리 설정 시 대상자의 팔 길이를 측정하여 그 길이에 비례 한 거리를 사용하여 팔거리 차이로 인한 오염변인을 줄이도록 하였

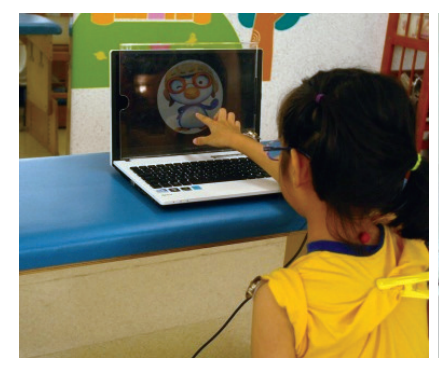

Target image

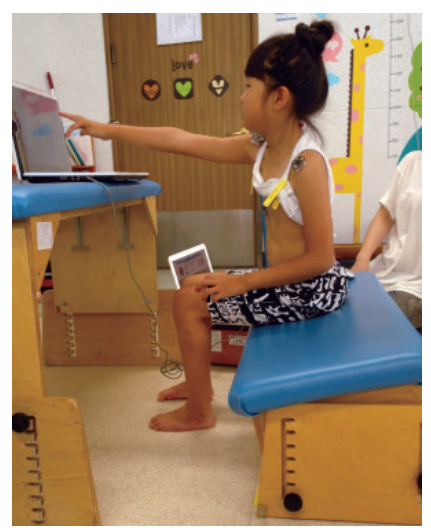

$15^{\circ}$ of anterior inclination

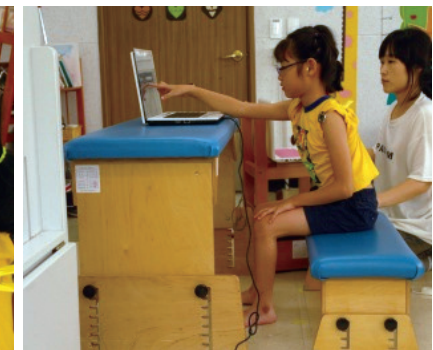

$0^{\circ}$ of inclination

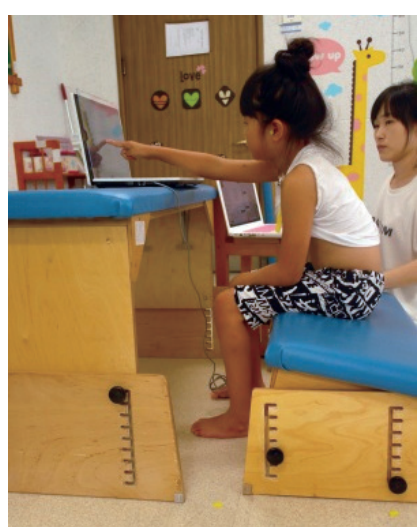

$15^{\circ}$ of posterior inclination
Figure 1. Schematic diagram of experimental process. 
다. 팔 길이는 실험에 사용되는 우세손의 어깨뼈봉우리에서 노뼈의 붓돌기기까지 측정하였다. 센서보드는 3 가지 위치에 부착하였다. 몸 통의 움직임을 측정하기 위한 제 1 센서는 복장뼈자루의 중심, 팔굽관 절의 움직임을 측정하기 위한 제 2 센서는 위팔뼈 가쪽관절 융기, 손 목관절의 움직임을 측정하기 위한 제 3센서는 자뼈의 붓돌기 위에 부착하였다.

$8 \mathrm{~cm}$ 크기의 캐릭터 목표물이 화면에 나타나면 팔을 뻗어 두번째 손가락 끝으로 목표물을 가르키도록 하였다. 이때 팔 이외의 다른 부 위에서 보상작용이 나타나지 않도록 체간은 유지하도록 지시하였다. 실험 전 모든 아동에게 평가 방법을 설명 한 후 편안한 의자에 앉아 1 회 연습하게 하였고, 스스로 편안한 속도로 가능한 자연스럽게 수행 하도록 하였다. 모든 대상자는 3 회 반복 측정하여 평균값을 사용하 였으며, 각 회 사이 3 분 동안 휴식을 갖게 하였다(Figure 1).

\section{3) 자료 분석 및 통계}

정상발달 아동과 뇌성마비 아동의 팔뻗기 수행능력을 알아보기 위하여 각 위치센서의 시작시간(reaction time), 목표물 도달에 걸리는 시간(movement time), 목표물 도달 시간 내 수집된 데이터 개수(data amount)를 구하였다. 팔뻗기 시작시간은 각 위치센서가 반응하기 시 작한 지점을 정하였다. 목표물 도달시간은 손목센서의 시간 데이터 를 이용하였으며, 손목 센서의 첫 움직임 시간과 이후 손목 센서의 Y 축 가속도 값이 0 이 되는 시점 사이를 목표물 도달 시간으로 정의하 였다. 목표물 도달 시간 내 수집된 데이터 개수는 일정 수준이상의 움 직임 발생 시 값을 수집하고 그룹화 하는 장비의 특징을 이용하여, 목 표물 도달 시간 내에서 각 센서별 수집된 데이터량을 분석하였다. 데 이터량은 팔 뻗기 동안 체간 및 상지의 움직임의 양적인 부분으로 해 석할 수 있으며 개수가 많을수록 팔 뻗기 시 흔들림, 움직임의 수정이 많았다는 것으로 해석하였다.

수집된 자료에 대한 모든 통계 분석은 SPSS for 22.0 (IBM Co., Armonk, NY, USA)을 이용하였다. 시작 시간과 목표물 도달시간은 개체 간 요인이 있고 개체 내 반복 요인이 두 개(위치센서 $3 \times$ 경사 3$)$ 인 반복 측정 반복분석을 실시하였으며, 목표물 도달시간은 개체 간 요인이 있고 반복요인이 하나(3 경사)인 반복측정 분산분석을 실시하였다. 각 집단 내에서의 위치센서와 경사도 간의 차이를 알아보기 위하여 시작시간과 목표물 도달 시간내의 데이터량은 개체 간 요인이 없는 이요인 반복측정 분산분석(위치센서 $3 \times$ 경사 3 )을 실시하였고, 목표 물 도달 시간은 일요인 분산분석을 실시하였다. 각 집단 내에서의 위 치센서와 경사도에 따른 변수들 간의 차이를 알아보기 위하여 일요 인 분산분석을 실시하였다. 반복 분석에 따른 차이를 알아보기 위하 여 본페로니 다중비교 검정(Bonferroni's multiple comparison test)을 실시하였다. 유의수준 $\alpha$ 는 0.05 로 정하였다.

\section{결 과}

\section{1. 연구 대상자의 일반적 특성}

본 연구는 정상발달 아동은 15 명(남자 7 명, 여자 8 명), 경직성 양하지 뇌성마비 아동 16 명(남자 8 명, 여자 8 명)으로 총 31 명을 대상으로 실시 하였다. 연구대상자의 일반적인 특성은 Table 1과 같다. 정상발달 아 동과 뇌성마비 아동의 성별, 나이, 신장, 체중, 팔 길이 모두 두 그룹 간 유의한차이가 없는 것으로 나타났다 $(\mathrm{p}>0.05)$ (Table 1).

\section{2. 팔뻗기 시작 시간}

집단 간 비교에서 팔뻗기 시작시간은 뇌성마비 아동이 정상발달 아 동에 비해 유의하게 지연되었으며 $(\mathrm{p}<0.05)$, 위치센서 간에는 유의한 차이가 있었으나 $(\mathrm{p}<0.05)$ 의자 경사도에서는 유의한 차이가 없었다 $(\mathrm{p}>0.05)$. 집단 내 비교에서 뇌성마비 아동은 위치센서 간에 유의한 차이가 있었으나 $(\mathrm{p}<0.05)$ 경사도에서는 유의한 차이가 없었으며 ( $\mathrm{p}>0.05)$, 정상발달 아동은 위치센서와 경사도 모두에서 유의한차이 가 나지 않았다 $(\mathrm{p}>0.05)$ (Table 2). 뇌성마비 아동의 사후검정 결과 $15^{\circ}$ 전방경사에서 몸통과 팔굽에서 유의한 차이가 있었다 $(\mathrm{p}<0.05)$.

\section{3. 목표물 도달 시간}

집단 간 비교에서 목표물 도달시간은 뇌성마비 아동이 정상발달 아 동에 비해 유의하게 지연되었으며 $(\mathrm{p}<0.05)$, 의자 경사도 간에는 유의 한 차이가 있었으나 $(\mathrm{p}<0.05)$. 집단 내 비교에서 뇌성마비 아동은 의자 경사도에 따라 목표물 도달 시간은 유의한 차이가 있었으나 $(\mathrm{p}<0.05)$ 정상발달 아동은 유의한 차이가 없었다 $(\mathrm{p}>0.05)$ (Table 3). 뇌성마비 아동의 사후검정 결과 뇌성마비 아동은 $15^{\circ}$ 전방경사와 $0^{\circ}$ 수평경사, $15^{\circ}$ 전방경사와 $15^{\circ}$ 후방경사에서 유의한 차이가 있었다 $(\mathrm{p}<0.05)$.

\section{4. 목표물 도달 시간 내 수집된 데이터량}

집단 간 비교에서 목표물 도달 시간 내 수집된 데이터량은 뇌성마비

Table 1. Demographic data of subjects

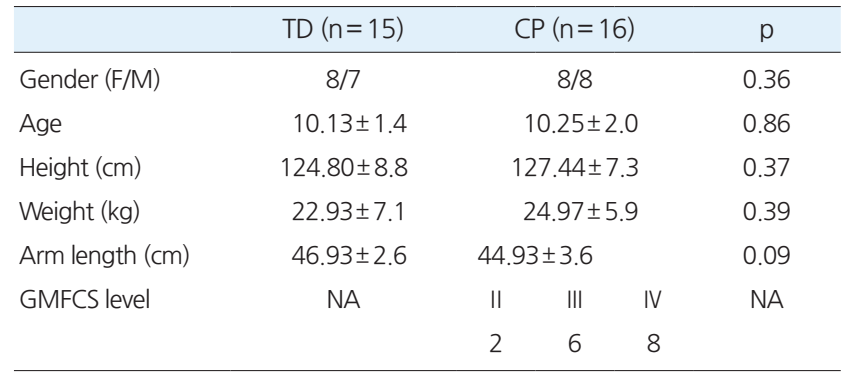

Values are mean \pm SD

Arm length, Calculated as distance from acromion to styloid process; GMFCS, Gross Motor Function Classification System; NA, Not applicable; TD, children with typical development; CP, children with spastic bilateral cerebral palsy. 
Table 2. Comparison of reaction time for reaching in the three seat surface inclination

\begin{tabular}{|c|c|c|c|c|c|c|c|c|}
\hline \multirow{2}{*}{ Variables } & \multicolumn{3}{|c|}{ TD } & \multirow{2}{*}{$\mathrm{p}$} & \multicolumn{3}{|c|}{$\mathrm{CP}$} & \multirow{2}{*}{$\mathrm{p}$} \\
\hline & Trunk & Elbow & Wrist & & Trunk & Elbow & Wrist & \\
\hline Ant $15^{\circ}$ & $0.15 \pm 0.08$ & $0.13 \pm 0.05$ & $0.17 \pm 0.08$ & 0.36 & $0.28 \pm 0.05$ & $0.19 \pm 0.06$ & $0.30 \pm 0.06$ & 0.01 * \\
\hline Horizontal & $0.16 \pm 0.11$ & $0.13 \pm 0.09$ & $0.17 \pm 0.10$ & 0.56 & $0.16 \pm 0.11$ & $0.22 \pm 0.11$ & $0.18 \pm 0.13$ & 0.60 \\
\hline Post $15^{\circ}$ & $0.19 \pm 0.09$ & $0.18 \pm 0.11$ & $0.16 \pm 0.09$ & 0.71 & $0.22 \pm 0.13$ & $0.20 \pm 0.10$ & $0.22 \pm 0.10$ & 0.39 \\
\hline $\mathrm{p}$ & 0.58 & 0.20 & 0.93 & & 0.10 & 0.73 & 0.15 & \\
\hline
\end{tabular}

TD, children with typical development; CP, children with spastic belateral cerebral palsy.

${ }^{*} \mathrm{p}<0.05$.

Table 3. Comparison of movement time for reaching in the three positions of seat surface inclination

\begin{tabular}{lcccc}
\hline Variables & Ant $15^{\circ}$ & Horizontal & Post $15^{\circ}$ & $\mathrm{p}$ \\
\hline TD & $1.86 \pm 0.26$ & $2.12 \pm 0.23$ & $2.25 \pm 0.26$ & 0.19 \\
CP & $4.34 \pm 0.25$ & $2.92 \pm 0.22$ & $3.05 \pm 0.25$ & $0.00^{*}$ \\
\hline
\end{tabular}

$T D$, children with typical development; $C P$, children with spastic belateral cerebral palsy. ${ }^{*} \mathrm{p}<0.05$.

Table 4. Comparison of data amount for reaching in the three positions of seat surface inclination

\begin{tabular}{|c|c|c|c|c|c|c|c|c|}
\hline \multirow{2}{*}{ Variables } & \multicolumn{3}{|c|}{ TD } & \multicolumn{5}{|c|}{$\mathrm{CP}$} \\
\hline & Trunk & Elbow & Wrist & $\mathrm{p}$ & Trunk & Elbow & Wrist & $p$ \\
\hline Ant $15^{\circ}$ & $7.93 \pm 0.92$ & $16.73 \pm 1.84$ & $19.07 \pm 1.77$ & 0.00 & $11.56 \pm 0.89$ & $24.06 \pm 1.78$ & $32.38 \pm 1.71$ & $0.00^{*}$ \\
\hline Horizontal & $6.53 \pm 0.58$ & $14.13 \pm 1.34$ & $18.13 \pm 1.56$ & 0.00 & $10.13 \pm 0.56$ & $20.50 \pm 1.30$ & $28.63 \pm 1.51$ & $0.00^{*}$ \\
\hline Post $15^{\circ}$ & $7.67 \pm 0.89$ & $14.13 \pm 1.48$ & $20.20 \pm 1.91$ & 0.00 & $10.81 \pm 0.86$ & $22.25 \pm 1.43$ & $27.56 \pm 1.85$ & $0.00^{*}$ \\
\hline$p$ & 0.53 & 0.42 & 0.52 & & 0.33 & 0.69 & 0.22 & \\
\hline
\end{tabular}

TD, children with typical development; CP, children with spastic belateral cerebral palsy. ${ }^{*} \mathrm{p}<0.05$.

아동이 정상발달 아동에 비해 유의하게 많았으며 $(\mathrm{p}<0.05)$, 의자 경사 도와 위치센서에 따라 유의한 차이가 있었다 $(\mathrm{p}<0.05)$. 집단 내 비교 에서 뇌성마비 아동과 정상발달 아동 모두 위치센서에 따라 유의한 차이가 있었으며 $(\mathrm{p}<0.05)$, 경사도에 따라서는 유의한 차이가 없었다 ( $\mathrm{p}>0.05)$ (Table 4). 사후 검정 결과 뇌성마비 아동과 정상발달 아동 모 두에서 각 경사도에서의 몸통 vs. 팔굽, 몸통 vs. 손목, 팔굽 vs. 손목의 위치 센서에서 유의한차이가 있었다 $(\mathrm{p}<0.05)$.

\section{고 찰}

팔 뻗기는 손을 이용한 조작과 결합되는 복잡한 과정으로, 상지 기능 의 중요한 요소 중 하나이다. 이러한 팔 뻗기는 자세 조절과 과제 의존 적 조절에 영향을 받으며, 이는 상지 재활에서 중요하게 고려되어야 할 요소이다. 특히 경직성 양하지 뇌성마비 아동에게 상지의 재활은 증진된 상지 기능을 얻어 독립적인 일상생활을 결정짓는 중요한 문 제이므로 이를 위한 지속적인 연구가 필요하다. ${ }^{10}$

의자 경사도는 앉은 자세에서 자세 조절 및 안정성, 신체 정렬과 중 심에 영향을 줄 수 있는 외부 환경적 요인으로, 다수의 연구에서 팔 뻗기에 영향을 줄 수 있다고 보고 하였다.11,12 또한 팔 뻗기 시 안정되
고 균형 있는 자세 조절을 위해 가장 중요한 것은 엉덩관절 각도라고 하였는데, 의자 경사는 고관절 각도를 별도의 장비 없이 간편하게 조 절 할 수 있고 일상생활 속에서 쉽게 적용할 수 있는 이점이 있다.11,13 이에 본 연구에서는 전방, 수평 및 후방 의자 경사도가 경직성 양하지 뇌성마비 아동의 팔뻗기 동작에 미치는 영향에 관하여 알아보고자 하였다.

본 연구의 결과에서 경직성 양하지 뇌성마비 아동이 정상 아동에 비해 팔 뻗기 시작 시간과 목표물 도달 시간이 지연되었으며, 팔 뻗기 도달 시간 내 수집된 데이터 개수가 많은 것으로 나타났다. Naslund 등 $^{14}$ 의 연구에서 팔 뻗기 시 정상발달 아동은 경직성 양하지 뇌성마 비 아동에 비해 움직임의 시간이 짧고, 움직임의 궤도가 부드러웠으 나, 경직성 양하지 뇌성마비 아동은 움직임의 시간이 지연되며, 움직 임의 궤도가 부드럽지 못한 형태라고 보고한 것과 유사한 결과이다. Shumway과 Woollacott ${ }^{3}$ 는 움직임 시간이 길고 협응성의 결여는 신경 학적 병변으로 인하여 광범위한 장애가 있는 환자의 팔 뻗기시 나타 나는 공통적인 특징이라고 하였다. 이는 경직성 양하지 뇌성마비 아 동들의 상지 기능 재활이 필요하며, 팔 뺃기는 상지의 움직임만으로 일어나는 단일 관절 움직임이 아니라 체간 및 신체 다른 분절과 협응 이 필요하다는 것을 보여주는 결과이다. 즉 성공적인 팔 뻗기가 이루 
어지기 위해서는 하나의 체계만 성숙해야 되는 것이 아니라 여러 가 지 체계들이 함께 성숙해야한다.

특히, 팔뻗기 동작 시 $15^{\circ}$ 전방 경사에서각 관절의 시작 시간의 순 서는 정상발달 아동과 뇌성마비 아동 모두 팔굽, 몸통, 손목 순으로 나타났다. 정상발달 아동의 경우 팔벋기 시작시간은 각 관절 간에 유 의한차이가 없었으나, 뇌성마비 아동의 경우 팔굽에 비해 몸통이 유 의하게 지연되어 시작되었다. 또한 최종 목표물 도달 시간에서는 정 상발달 아동의 경우 $15^{\circ}$ 전방 경사, $0^{\circ}$ 수평 경사, $15^{\circ}$ 후방 경사 순으로 나타났으며 유의한 차이는 없었다. 반면, 뇌성마비 아동은 $0^{\circ}$ 수평 경 사, $15^{\circ}$ 후방 경사, $15^{\circ}$ 전방 경사순으로 나타났으며 경사도 간에 유의 한 차이가 있었다. 이러한 결과는 정상발달 아동의 경우 전방경사 의 자는 허리의 압굽이를 증가시키고 자세 안정성을 개선하여 체간과 상지의 협응 작용을 원활하게 만들어주었기 때문일 것이다. 반면 뇌 성마비 아동은 체간 및 자세조절력, 자세 안정성의 저하로 팔 뻗기시 의자 경사도와 같은 환경적 변화에 더욱 민감하게 반응하기 때문에 전방경사 의자에서 팔뻗기 수행능력이 감소하였을 것으로 보인다.

McClenaghan 등 ${ }^{16}$ 은 의자경사도는 뇌성마비 아동의 팔 뻗기 능력 에 영향을 미치며, 중립과 후방 경사 자세가 더 좋았다고 하였으며, Nwaobi 등 15 은 수평된 의자 경사가 허리폄근과 엉덩관절 모음근의 근 활성을 줄여서 상지 기능을 좋게 한다고 하였다는 결과와 일치한다. 이는 몸통의 안정성이 부족한 경직성 양하지 뇌성마비 아동이 불완 전한 자세를 보상하기 위해 등을 앞으로 구부리고, 어깨를 움츠리며 비정상적 후방 골반 경사를 갖는 일반적인 특징과 몸통조절을 보상 하기 위해 엉덩관절을 중립이상으로 굽힘시켜 폄근 반사를 억제하 고, 부족한 체간 조절능력을 보상하기 때문이다.1718 즉, 비정상적인 몸 통 굽힘과 골반의 후방 경사를 통한 보상 움직임은 항중력적인 동작 의 어려움을 가중 시키고, 체간 및 주변근 활동을 억제하여 상지와 협응을 방해하고, 비정상적인 정렬 상태를 만들어 2 차적 변형, 비대 칭, 근 약화 등의 문제를 가져와 장기적으로는 상지의 기능적 활동과 호흡 및 발성 기능까지 방해할 수 있다.

인간공학적 접근은 뇌성마비 아동의 자세조절 능력을 개선시키기 간편한 방법으로 인식되어져 왔다. 특히 휄체어에서 많은 시간을 보 내는 학력기의 뇌성마비 아동의 경우 의자경사도를 통한 치료적 접 근은 더욱 의미가 크다고 볼 수 있다. 후방경사 의자가 보상적 자세조 절을 유발하여 팔뻗기를 용이하게 한다면, 전방경사 의자는 손상된 자세조절 능력을 개선시키고 이를 바탕으로 팔뻗기 수행능력을 개선 시키는 치료적 접근법이 될 수 있다. 그러나, 장기간 동안 전방경사 의 자에 앉아 있는 경우는 과도한 허리 앞굽이증과 요통과 같은 잠재적 인 문제를 유발할 수 있으므로, 이러한치료적 접근은 앉기 자세의 주 기적인 평가와 함께 동반되어야 할 것이다.

이상의 결과로 의자경사도는 팔뻗기에 유의한 영향을 미치는 것으
로 확인되었으며, 경직성 양하지 뇌성마비 아동은 이를 고려한 중재 가 필요함을 알 수 있었다. 본 연구의 제한점은 연구대상자가 GMFCS 레벨 II에서 IV까지 넓게 퍼져있어 연구 결과에 영향을 미쳤을 것으 로 사료된다. 추후 연구에서는 각 GMFCS 레벨에서 따른 의자 경사도 의 영향을 연구할 필요가 있다고 여겨진다. 또한 연구 결과를 일반화 하기에는 대상자의 수가 적었으며, 일상생활에서 사용되는 다양한 환경에서 목적 있는 팔 뻗기 동작을 대표하기는 부족하여 실제 기능 적 상지 능력과 차이가 있을 수 있다. 이에 향후 보다 다양하고 목적 있는 팔 뻗기에 대한 광범위한 연구가 필요할 것이다.

\section{ACKNOWLEDGEMENT}

이 논문은 2012년도 대구가톨릭대학교 교내연구비 지원에 의한 것임.

\section{REFERENCES}

1. Page SJ, Elovic E, Levine P, et al. Modified constraint-induced therapy and botulinum toxin a: A promising combination. Am J Phys Med Rehabil. 2003;82(1):76-80.

2. Saxena S, Rao BK, Kumaran S. Analysis of postural stability in children with cerebral palsy and children with typical development: An observational study. Pediatr Phys Ther. 2014;26(3):325-30.

3. Shumway-Cook A, Woollacott MH. Motor control: Translating research into clinical practice third edition Liooincott Williams \& Wilkins, 2007.

4. Levin MF, Michaelsen SM, Cirstea CM, et al. Use of the trunk for reaching targets placed within and beyond the reach in adult hemiparesis. Exp Brain Res. 2002;143(2):171-80.

5. Fitts PM. The information capacity of the human motor system in controlling the amplitude of movement. J Exp Psychol. 1954;47(6):381-91.

6. Bax MC, Flodmark O, Tydeman C. Definition and classification of cerebral palsy. From syndrome toward disease. Dev Med Child Neurol Suppl. 2007;109:39-41.

7. Sritipsukho P, Mahasup N. Correlations between gross motor functions and health-related quality of life in thai children with spastic diplegia. J Med Assoc Thai. 2014;97 Suppl 8:S199-204.

8. Bangash AS, Hanafi MZ, Idrees R, et al. Risk factors and types of cerebral palsy. J Pak Med Assoc. 2014;64(1):103-7.

9. Heyrman L, Feys H, Molenaers G, et al. Altered trunk movements during gait in children with spastic diplegia: Compensatory or underlying trunk control deficit? Res Dev Disabil. 2014;35(9):2044-52.

10. Sandlund M, Domellof E, Grip H, et al. Training of goal directed arm movements with motion interactive video games in children with cerebral palsy - a kinematic evaluation. Dev Neurorehabil. 2014;17(5):318-26.

11. Shin HK, Ryu YU. The effects of seat surface inclination on the onset of muscle contraction during sit-to-stand in healthy adult. J Korean Soc Phys Ther. 2012;24(6):383-7.

12. Tsai YS, Yu YC, Huang PC, et al. Seat surface inclination may affect postural stability during boccia ball throwing in children with cerebral palsy. Res Dev Disabil. 2014;35(12):3568-73. 
13. Bergen AF. Physical rehabilitation assessment and treatment. Philadelphia, F.A. davis 1994.

14. Naslund A, Sundelin G, Hirschfeld H. Reach performance and postural adjustmentsduring standing in children with severe spastic diplegia using dynamic ankle-foot orthoses. J Rehabil Med. 2007;39(9):715-23.

15. Nwaobi OM, Brubaker CE, Cusick B, et al. Electromyographic investigation of extensor activity in cerebral-palsied children in different seating positions. Dev Med Child Neurol. 1983;25(2):175-83.
16. McClenaghan BA, Thombs L, Milner M. Effects of seat-surface inclination on postural stability and function of the upper extremities of children with cerebral palsy. Dev Med Child Neurol. 1992;34(1):40-8.

17. Hadders-Algra M, van der Heide JC, Fock JM, et al. Effect of seat surface inclination on postural control during reaching in preterm children with cerebral palsy. Phys Ther. 2007;87(7):861-71.

18. Barbara ABS, Glen G, Marjorie S, et al. Willard and spackman's occupational therapy. LWW, 2013. 